\title{
Genetic and phylogenetic analysis of dissimilatory iodate-reducing bacteria identifies potential niches across the world's oceans
}

\author{
Victor Reyes-Umana ${ }^{1}$, Zachary Henning $^{1}$, Kristina Lee ${ }^{1}$, Tyler P. Barnum ${ }^{1}$, John D. Coates ${ }^{1}$
}

${ }^{1}$ Department of Plant and Microbial Biology, University of California, Berkeley, CA 94720, USA

\section{Abstract}

Iodine is oxidized and reduced as part of a biogeochemical cycle that is especially pronounced in the oceans, where the element naturally concentrates. The use of oxidized iodine in the form of iodate $\left(\mathrm{IO}_{3}{ }^{-}\right)$as an electron acceptor by microorganisms is poorly understood. Here, we outline genetic, physiological, and ecological models for dissimilatory $\mathrm{IO}_{3}{ }^{-}$reduction to iodide (I') by a novel estuarine bacterium, Denitromonas iodocrescerans strain IR-12, $s p$. nov. Our results show that dissimilatory iodate reduction (DIR) by strain IR-12 is molybdenum-dependent and requires an $\mathrm{IO}_{3}{ }^{-}$reductase $(i d r A)$ and likely other genes in a mobile cluster with a conserved association across known and predicted DIR microorganisms (DIRM). Based on genetic and physiological data, $\mathrm{IO}_{3}{ }^{-}$is likely reduced to hypoiodous acid (HIO), which rapidly disproportionates into $\mathrm{IO}_{3}{ }^{-}$ and iodide $\left(\mathrm{I}^{-}\right)$, in a respiratory pathway that provides an energy yield equivalent to that of nitrate or perchlorate respiration. Consistent with the ecological niche expected of such a metabolism, $i d r A$ is enriched in the metagenome sequence databases of marine sites with a specific biogeochemical signature and diminished oxygen. Taken together, these data suggest that DIRM help explain the disequilibrium of the $\mathrm{IO}_{3}{ }^{-}: \mathrm{I}^{-}$concentration ratio above oxygen minimum zones and support a widespread iodine redox cycle mediated by microbiology.

Introduction

Iodine (as ${ }^{127} \mathrm{I}$ ) is the heaviest stable element of biological importance and an essential component of the human diet due to its role in thyroxine biosynthesis in vertebrates ${ }^{1-3}$. Iodine is enriched in marine environments where it exists in several oxidation states, reaching concentrations of up to $450 \mathrm{nM}^{4}$. In these environments, organisms such as kelp bioconcentrate iodine as iodide $\left(\mathrm{I}^{-}\right)$and produce volatile iodine species such as methyl iodide ${ }^{5}$. These volatile iodine species contribute to the destruction of tropospheric ozone (a major greenhouse gas) and aerosol formation at the marine boundary layer, consequently resulting in cloud formation and other local climatic effects ${ }^{1,6}$. Despite the global biological and geochemical importance of iodine, little is known about its biogeochemistry in the ocean ${ }^{4}$. For instance, the biological mechanism accounting for the unexpected chemical disequilibrium between $\mathrm{I}^{-}$and iodate $\left(\mathrm{IO}_{3}^{-}\right)$in seawater $\left(\mathrm{I}^{-}: \mathrm{IO}_{3}^{-}\right.$ disequilibrium) remains unknown ${ }^{4}$. At the physicochemical conditions of seawater, iodine is most stable as $\mathrm{IO}_{3}^{-7}$, yet measurements of $\mathrm{IO}_{3}^{-}$and $\mathrm{I}^{-}$in regions with high biological productivity (e.g., marine photic zones, kelp forests, or sediments), reveal an enrichment of the $\mathrm{I}^{-}$ion beyond what can be explained through abiotic reduction ${ }^{7,8}$.

39 Among numerous explanations proposed for $\mathrm{I}^{-}$enrichment, microbial $\mathrm{IO}_{3}{ }^{-}$reduction is particularly

40 compelling. The high reduction potential $\left(\mathrm{IO}_{3}^{-} / \mathrm{I}^{-} E_{h}=0.72 \mathrm{~V} \text { at } \mathrm{pH} 8.1\right)^{7,9}$ makes $\mathrm{IO}_{3}^{-}$an ideal

41 electron acceptor for microbial metabolism in marine environments. Early studies indicated 
common microorganisms such as Escherichia coli and Shewanella putrefaciens, reduce $\mathrm{IO}_{3}{ }^{-}$to I' 9,10. Subsequent studies associated this metabolism with the inadvertent activity of DMSO respiratory reductase enzymes in marine environments, along with specific enzymes (i.e., perchlorate reductase, nitrate reductase) that reduce $\mathrm{IO}_{3}{ }^{-}$in vitro ${ }^{9,11,12}$. However, there is little evidence that organisms hosting these enzymes are capable of growth by $\mathrm{IO}_{3}{ }^{-}$reduction. While inadvertent $\mathrm{IO}_{3}{ }^{-}$reduction might be mediated by marine bacteria possessing DMSO reductases, until recently, no definitive evidence existed that global $\mathrm{IO}_{3}{ }^{-}$reduction is a microbially assisted phenomenon.

In support of a microbial role for the observed $\mathrm{I}^{-}: \mathrm{IO}_{3}{ }^{-}$disequilibrium, previous studies demonstrated that at least one member each of the common marine genera Pseudomonas and Shewanella are capable of $\mathrm{IO}_{3}^{-}$reduction ${ }^{12-14}$. More recently, $\mathrm{IO}_{3}^{-}$reduction by Pseudomonas sp. strain SCT was associated with a molybdopterin oxidoreductase closely related to arsenite oxidase $^{14}$. As part of this work, a dedicated biochemical pathway was proposed involving two peroxidases associated with a heterodimeric $\mathrm{IO}_{3}{ }^{-}$reductase $(\mathrm{Idr})^{14}$. The putative model proposes a four-electron transfer mediated by Idr, resulting in the production of hydrogen peroxide and hypoiodous acid ${ }^{14}$. Two peroxidases detoxify the hydrogen peroxide while a chlorite dismutase (Cld) homolog dismutates the hypoiodous acid into $\mathrm{I}^{-}$and molecular oxygen, which is subsequently reduced by the organism ${ }^{14}$. The proposed pathway involving a molecular $\mathrm{O}_{2}$ intermediate is analogous to canonical microbial perchlorate respiration ${ }^{15}$. By contrast, Toporek et al. ${ }^{18}$ using the $\mathrm{IO}_{3}{ }^{-}$respiring Shewanella oneidensis demonstrated the involvement of a multiheme cytochrome not found in Pseudomonas sp. strain SCT suggesting an alternative DIR pathway. The disparate mechanisms underscore the potential diversity of $\mathrm{IO}_{3}^{-}$respiratory processes. As such, identification of additional DIR microorganisms (DIRM) would clarify which genes are required for this metabolism and enable identification of $\mathrm{IO}_{3}{ }^{-}$respiratory genes in metagenomes.

With this as a primary objective, we identified a novel marine DIRM, Denitromonas iodocrescerans strain IR-12, sp. nov, that obtained energy for growth by coupling $\mathrm{IO}_{3}{ }^{-}$reduction to acetate oxidation. Taxonomic analysis placed this organism in the Denitromonas genus commonly associated with marine environments ${ }^{19}$. We used comparative genomics to identify the core genes involved in $\mathrm{IO}_{3}{ }^{-}$respiration, which formed a distinct mobile genomic island. Reverse genetics, physiology, and comparative genomic data were used to propose a new model for DIR, with a confirmed role for a molybdopterin-dependent $\mathrm{IO}_{3}{ }^{-}$reductase $(\mathrm{Idr} A B)^{14}$. A phylogenetic analysis was used to establish the distribution of this metabolism across the tree of life and measure the degree to which the genomic island is subject to horizontal gene transfer. Finally, metagenomic analysis identified the $i d r A$ gene in the Tara oceans datasets, enabling the correlation of DIR populations with ocean chemistry. These results together enabled the proposed model for the global distribution of the DIR metabolism and the ecology of the microorganisms involved.

\section{Results and discussion}

\section{Isolation of D. iodocrescerans}

81 D. iodocrescerans was isolated under anoxic conditions from estuarine sediment samples by 82 selective enrichment followed by single colony isolation on agar plates. Analysis of the 16S rRNA 
indicated an axenic culture composed of a single phylotype (strain IR12) belonging to the Denitromonas genus in the beta proteobacteria identical to an uncultured Denitromonas clone from a metagenomic sample (GenBank: KF500791.1) (Figure 1A). The closest cultured relatives were D. indolicum strain MPKc ${ }^{20}$ (GenBank: AY972852.1, 99.46\% similarity) and D. aromaticus (GenBank: AB049763.1, 99.40\% similarity). Morphologically, strain IR12 is a rod-shaped motile cell $1-2 \mu \mathrm{m}$ long and $0.5 \mu \mathrm{m}$ diameter with a single polar flagellum (Figure 1B). Based on its phylogenetic affiliation, morphology, and metabolism (described below) we propose that strain IR12 represents a new species in the Denitromonas genus with the epitaph $D$. iodocrescerans.

\section{Physiology and energetics of $D$. iodocrescerans}

Cells of $D$. iodocrescerans grew on basal medium with acetate and $\mathrm{IO}_{3}{ }^{-}$as the sole electron donor and acceptor, respectively (Figure $1 \mathrm{C}$ and $\mathrm{D}$ ). Ion chromatography and growth studies revealed that $\mathrm{IO}_{3}{ }^{-}$was quantitatively reduced to $\mathrm{I}^{-}$with concomitant cell density increase. No growth or acetate consumption occurred in the absence of $\mathrm{IO}_{3}{ }^{-}$. Similarly, no $\mathrm{IO}_{3}{ }^{-}$reduction occurred in the absence of acetate or in heat killed controls. These results indicated that $\mathrm{IO}_{3}{ }^{-}$reduction was enzymatically mediated coupled to acetate oxidation and growth. Acetate-free control cultures reduced micromolar amounts of $\mathrm{IO}_{3}{ }^{-}(114 \pm 34 \mu \mathrm{M}$, mean \pm standard deviation, $\mathrm{n}=3)$ which was attributable to residual acetate carried over from the inoculum (Error! Reference source not found.). D. iodocrescerans consumed $2.46 \pm 0.499 \mathrm{mM} \mathrm{IO}_{3}^{-}$(mean \pm standard deviation, $\mathrm{n}=3$ ) while oxidizing $2.86 \pm 0.427 \mathrm{mM}$ acetate (mean \pm standard deviation, $\mathrm{n}=3$ ) with a final optical density $\left(\mathrm{OD}_{600}\right)$ increase of 0.109 . This is equivalent to an average stoichiometry of $0.86 \mathrm{~mol} \mathrm{IO}_{3}{ }^{-}$ per mol acetate. The morphological consistency between $D$. iodocrescerans and E. coli, suggests that an $\mathrm{OD}_{600}$ increase of 0.39 is equivalent to 1 gram of cell dry weight ${ }^{21}$ and that $\sim 50 \%$ of cell dry weight is comprised of carbon ${ }^{22}$. Using these numbers, the corrected stoichiometry accounting for acetate incorporation into cell mass is $93 \%$ of the theoretical value according to:

$$
3 \mathrm{CH}_{3} \mathrm{COOH}+4 \mathrm{IO}_{3}^{-} \rightarrow 6 \mathrm{CO}_{2}+4 \mathrm{I}^{-}+6 \mathrm{H}_{2} \mathrm{O}
$$

Our calculations indicate that $30.72 \%$ of total carbon is assimilated into biomass while the remaining is respired. Such a result is typical for highly oxidized electron acceptors such as oxygen, nitrate, or perchlorate ${ }^{15,23}$. In support of this, the calculated Gibb's free energy and the change in enthalpy for the reduction of $\mathrm{IO}_{3}{ }^{-}$per mole of electrons transferred is $-115 \mathrm{~kJ} / \mathrm{mol} \mathrm{e}$ and $-107 \mathrm{~kJ} / \mathrm{mol}$ e- respectively ${ }^{24}$. These values place the energy provided through $\mathrm{IO}_{3}{ }^{-}$respiration akin to that of perchlorate respiration $\left(\mathrm{ClO}_{4}{ }^{-} / \mathrm{Cl}^{-}, E^{o}=+0.797 \mathrm{~V}\right){ }^{15}$, and between that of aerobic respiration $\left(\mathrm{O}_{2} / \mathrm{H}_{2} \mathrm{O}, E^{o}{ }^{o}=+0.820 \mathrm{~V}\right)$ and nitrate reduction $\left(\mathrm{NO}_{3}{ }^{-} / \mathrm{N}_{2}, E^{o}{ }^{\prime}=+0.713 \mathrm{~V}\right)^{25}$. This suggests a similar degree of carbon assimilation would be expected for $\mathrm{IO}_{3}{ }^{-}$respiration ${ }^{23}$.

\section{DIR is molybdate dependent}

The reduction of oxyanions like $\mathrm{IO}_{3}^{-}$, such as bromate, chlorate, perchlorate, and nitrate, is typically catalyzed by enzymes belonging to the DMSO reductase superfamily of molybdopterin oxidoreductases $^{26}$. These enzymes require molybdenum as a cofactor in order to donate two 
electrons at a time to the receiving molecule ${ }^{27}$. To determine if phenotypic $\mathrm{IO}_{3}{ }^{-}$reduction was molybdenum-dependent, we passaged $D$. iodocrescerans six times in aerobic, molybdate-free minimal media to remove any trace molybdenum as described in Chaudhuri et al ${ }^{28}$. As expected, and similarly to observations with perchlorate reducing microorganisms ${ }^{28}$, omitting molybdenum from the oxic medium did not affect the aerobic growth of $D$. iodocrescerans (data not shown). In contrast, no growth or $\mathrm{IO}_{3}^{-}$reduction was observed when these cells were passaged into molybdenum-free anoxic media with $\mathrm{IO}_{3}{ }^{-}$as the electron acceptor (Figure 1E). When $0.1 \mathrm{mM}$ sodium molybdate was added into the non-active cultures at 14 hours post inoculation, growth and $\mathrm{IO}_{3}{ }^{-}$resumed (Figure 1E). These results demonstrate that $\mathrm{IO}_{3}{ }^{-}$respiration by D. iodocrescerans is molybdenum dependent and are consistent with the involvement of a DMSO oxidoreductase in $\mathrm{IO}_{3}^{-}$reduction ${ }^{28}$.

\section{Core genes required for DIR}

To identify the genes required for $\mathrm{IO}_{3}{ }^{-}$respiration we performed a comparative genomic analysis between the genomes of the $\mathrm{IO}_{3}{ }^{-}$respiring species (D. iodocrescerans and Pseudomonas sp. SCT), and the non- $\mathrm{IO}_{3}^{-}$respiring close relatives (D. halophilus SFB-1, and Pseudomonas sp. CAL). Additionally, Pseudomonas and Denitromonas form phylogenetically distinct genera (Gammaproteobacteria and Betaproteobacteria, respectively), reducing the likelihood of shared gene content ${ }^{29}$. We surmised that DIRM must share a unique gene (or set of genes) that enables $\mathrm{IO}_{3}{ }^{-}$reduction. This comparison identified 26 genes uniquely shared by the two DIRM and not found in the closely related non- $\mathrm{IO}_{3}{ }^{-}$respiring species (Figure 2A; Table S2). Four of these genes were present in a gene cluster that contained genes for alpha and beta subunits of a DMSO reductase family molybdopterin enzyme related to arsenite oxidase (AioAB) ${ }^{30}$ supporting our result of a molybdenum dependency for this metabolism. The remaining two genes in the cluster were closely related to cytochrome $\mathrm{C}$ peroxidases $c c p 1$ and $c c p 2$, possibly involved electron shuttling and oxidative stress responses ${ }^{31,32}$. These four genes were similar to those identified by Yamazaki et al. under the proposed nomenclature $i d r \mathrm{~A}, i d r \mathrm{~B}, i d r \mathrm{P}_{1}, i d r \mathrm{P}_{2}$ for Pseudomonas sp. $\mathrm{SCT}^{14}$ (Figure $2 \mathrm{~B}$ ). A SignalP analysis showed that $i d r \mathrm{P}_{1}$ and $i d r \mathrm{P}_{2}$ possessed a signal sequence for periplasmic secretion via the Sec pathway, while $i d r \mathrm{~B}$ used the Tat pathway ${ }^{33}$. By contrast $i d r \mathrm{~A}$ did not have a signal peptide sequence, suggesting its protein product is co-transported with IdrB into the periplasm ${ }^{34}$. Based on this evidence, we concluded that dissimilatory $\mathrm{IO}_{3}{ }^{-}$reduction in D. iodocrescerans occurs entirely in the periplasm, consistent with the observation by Amachi et al. that associated $\mathrm{IO}_{3}{ }^{-}$reductase activity in the periplasmic fractions of Pseudomonas strain SCT 13. Notably, the gene cluster lacked a quinone oxidoreductase suggesting that $D$. iodocrescerans involves the expression of a non-dedicated quinone oxidoreductase.

Evidence associating $\mathrm{IdrAB}$ to DIR, currently relies on the $\mathrm{IO}_{3}{ }^{-}$consuming activity of crude cell extracts of Pseudomonas strain SCT and differential expression of $i d r A B P_{1} P_{2}$ under $\mathrm{IO}_{3}{ }^{-}$reducing conditions $^{14}$. To validate the association between these genes and DIR in D. iodocrescerans, we developed a genetic system to perform targeted knockouts (see Table S1 and supplemental methods for details). The idrA gene was targeted since its associated molybdenum cofactor ultimately mediates the reduction of the oxyanion ${ }^{26}$. Upon introduction of an in-frame deletion at the $i d r A$ locus, the organism was incapable of growth via $\mathrm{IO}_{3}{ }^{-}$respiration (Figure $2 \mathrm{C}$ ) while growth under oxic conditions remained unimpaired. Complementation of $i d r A$ on a low copy number 
vector ( $\mathrm{pVR}$ 065) restored the $\mathrm{IO}_{3}{ }^{-}$respiring phenotype demonstrating that the $i d r A$ gene is a prerequisite to enable $\mathrm{IO}_{3}^{-}$respiration (Figure 2C). Our identification of a second DIRM, in addition to Pseudomonas strain $\mathrm{SCT}$, with an $\mathrm{IdrAB}$ suggests that $\mathrm{IO}_{3}{ }^{-}$reduction requires a specialized molybdopterin oxidoreductase, and that other molybdopterin oxidoreductases in the genome cannot rescue the phenotype. Furthermore, our work demonstrates a distinct difference from $\mathrm{IO}_{3}{ }^{-}$reduction by the multiheme cytochrome in Shewanella and suggests that the ability to reduce $\mathrm{IO}_{3}{ }^{-}$may have evolved at least twice independently.

\section{An alternative DIR model}

The current model for $\mathrm{IO}_{3}^{-}$respiration by Pseudomonas strain SCT proposes the donation of electrons from the quinone pool via a cytochrome $\mathrm{c}$ to $\mathrm{IdrAB}$, to initiate reduction of $\mathrm{IO}_{3}{ }^{-}$to $\mathrm{HIO}$ and $\mathrm{H}_{2} \mathrm{O}_{2} . \mathrm{H}_{2} \mathrm{O}_{2}$ is reduced to $\mathrm{H}_{2} \mathrm{O}$ by the peroxidases $\mathrm{IdrP}_{1}$ and $\mathrm{IdrP}_{2}$, while a chlorite dismutase (Cld)-like enzyme converts $\mathrm{HIO}$ to $\mathrm{I}^{-}$and $1 / 2 \mathrm{O}_{2}$, a catalytic function that has never been demonstrated for Cld or Cld-like proteins ${ }^{14}$. The resultant oxygen is then further respired to $\mathrm{H}_{2} \mathrm{O}$ by a terminal oxygen reductase. The putative participation of a Cld-like protein was based on expression data rather than empirically determined activity ${ }^{14}$. Furthermore, comparative genomics does not support the general involvement of $\mathrm{Cld}$ in $\mathrm{IO}_{3}{ }^{-}$respiration, as $c l d$ is never co-located with the IRI and is notably absent from all but two of the 145 putative DIRM genomes identified in NCBI GenBank (see below) including the genome of $D$. iodocrescerans.

Since $D$. iodocrescerans genome lacks $c l d$-like genes, we propose that the primary mechanism of $\mathrm{IO}_{3}^{-}$respiration by this organism relies on the complex and reactive chemistry of iodine oxyanions $^{35}$ and that the peroxidases $\operatorname{IdrP}_{1}$ and $\mathrm{IdrP}_{2}$ serve a critical detoxification role for inadvertent oxidants generated rather than being central components of the pathway itself. In the D. iodocrescerans model (Figure 3A), IdrAB accepts electrons from cytochrome c551, and performs a four-electron transfer, similarly to the mechanism of perchlorate reductase $(\mathrm{Pcr})^{36}$, with a resultant production of the chemically unstable intermediate hypoiodous acid (HIO). This intermediate then undergoes abiotic disproportionation to yield $\mathrm{I}^{-}$and $\mathrm{IO}_{3}{ }^{-}$as reported in alkaline aquatic environments ${ }^{16,37}$, and is simplistically represented by the following equation:

$$
3 \mathrm{HIO} \rightarrow 2 \mathrm{I}^{-}+\mathrm{IO}_{3}^{-}+3 \mathrm{H}^{+}
$$

The resultant $\mathrm{IO}_{3}{ }^{-}$subsequently cycles back into the reductive pathway. In this manner, the cell completes the 6-electron reduction of $\mathrm{IO}_{3}{ }^{-}$to $\mathrm{I}^{-}$without invoking a Cld-like enzyme with putative capacity to dismutate $\mathrm{IO}^{-}$to $\mathrm{I}^{-}$and $\mathrm{O}_{2}$. This model is similar to the cryptic model for some species of perchlorate reducing microorganism which rely on the chemical reactivity of the unstable pathway intermediate chlorite $\left(\mathrm{ClO}_{2}^{-}\right)$with reduced species of iron or sulfur to prevent toxic inhibition ${ }^{36,38}$. We propose that the initial reduction of $\mathrm{IO}_{3}{ }^{-}$at the $\mathrm{IdrA}$ inadvertently produces low levels of incidental toxic $\mathrm{H}_{2} \mathrm{O}_{2}$. This is analogous to the production of hypochlorite $\left(\mathrm{ClO}^{-}\right)$by respiratory perchlorate reducing microorganisms during respiration of perchlorate or chlorate ${ }^{39,40}$. To protect themselves from this reactive chlorine species, perchlorate respiring organisms have evolved a detoxifying mechanism based on redox cycling of a sacrificial methionine rich peptide ${ }^{40}$. In the $D$. iodocrescerans model for $\mathrm{IO}_{3}{ }^{-}$respiration the cytochrome c peroxidases play the critical detoxification role against inadvertent $\mathrm{H}_{2} \mathrm{O}_{2}$ production, rather than a central role for the reductive 
pathway as proposed for Pseudomonas strain $\mathrm{SCT}^{14}$ (Figure 3A). Such a model is not only parsimonious with the predicted biochemistries and abiotic reactivities of the proteins and iodine oxyanions involved but is also consistent with the micromolar quantities of $\mathrm{H}_{2} \mathrm{O}_{2}$ observed by Yamazaki et al. during the reduction of millimolar quantities of $\mathrm{IO}_{3}^{-}$by Pseudomonas strain $\mathrm{SCT}^{14}$.

\section{Evolutionary history of DIR}

Core genes for DIR were used to define the phylogenetic distribution of this metabolism. Close homologs to the catalytic subunit of IdrA were identified among genomes in NCBI GenBank. A phylogenetic tree of the DMSO reductase family (Figure 4A and 4B) confirms previous results indicating that arsenite oxidase alpha subunit (AioA) is the most closely related characterized enzyme to IdrA ${ }^{14}$. The extent of the IdrA clade was difficult to define because IdrA from $D$. iodocrescerans and Pseudomonas sp. SCT are closely related. To determine whether more IdrA homologs in this clade function as $\mathrm{IO}_{3}{ }^{-}$reductases or arsenite oxidases, we performed a gene neighborhood analysis looking at the 10 genes both upstream and downstream of either the idrA or aioA locus and clustered them using MMseqs $2^{41}$ (Figure 5). We observed a clear distinction in neighborhood synteny between genes mostly closely to $i d r A$ versus those most closely related to $a i o A$. All neighborhoods in the $i d r A$ clade showed conserved synteny at $i d r A B P_{1} P_{2}$ (Figure 5), whereas organisms with an AioA, showed an alternative gene structure, notably missing the cytochrome $\mathrm{c}$ peroxidases. Based on this pattern, all organisms possessing $i d r A B P_{1} P_{2}$ genes are likely DIRM. The outgroups of $\mathrm{IO}_{3}{ }^{-}$reductase in this phylogeny are homologs found in Halorubrum spp., which are known to oxidize arsenite ${ }^{42}$, and a Dehalococcodia bacterium (GCA_002730485.1), which also lacks the cytochrome c peroxidases in its gene neighborhood (Figure 5). Further research into these proteins may provide more information on the transition from arsenite oxidase to $\mathrm{IO}_{3}{ }^{-}$reductase.

Genes mediating $\mathrm{IO}_{3}{ }^{-}$reduction were identified in 145 genomes from bacteria in the Alphaproteobacteria, Betaproteobacteria, and Gammaproteobacteria. Deeper branching members included members of Planctomycetaceae and several others belonging to the Candidate Phyla Radiation group such as, Ca. Rokubacteria, Ca. Lindowbacteria, and NC10 (Figure 4B) (3- $^{4}$ 45. DIR seemed most prevalent in the phylum Proteobacteria, which is a pattern that has been observed for some other rare metabolisms ${ }^{46}$. The discordance between the taxonomy of the host organisms and the phylogeny of IdrA (Figure 4B; Figure S1) ${ }^{47}$ suggested that DIR is a horizontally transferred metabolism. For example, IdrA in the Gammaproteobacterium Pseudomonas sp. SCT was most closely related to IdrA in Betaproteobacteria such as Azoarcus sp. DN11. Additional evidence for horizontal gene transfer in individual genomes included insertion sites at the 3 ' end of tRNAs, a skew in GC content, and association with other horizontally transferred genes ${ }^{48,49}$. In D. iodocrescerans, there was no significant GC skew, but we observed a tRNA ${ }^{\text {Gly }}$ roughly $72 \mathrm{kbp}$ downstream of the $i d r A B P_{1} P_{2}$ locus. While we did not detect inverted repeats, Larbig et al. previously demonstrated an integration site in P. stutzeri at tRNA ${ }^{\mathrm{Gly} 50}$. Additionally, numerous heavy metal resistance markers, like mer and cus genes, were found near the $i d r A B P_{1} P_{2}$ locus $(1.2$ $\mathrm{kbp}$ and $22 \mathrm{kbp}$ away respectively), further suggesting horizontal transfer ${ }^{48,51,52}$. A method to detect genomic islands in complete genomes predicted the $i d r A B P_{1} P_{2}$ locus to be its own $5.8 \mathrm{kbp}$ genomic island in Azoarcus sp. DN11, which has a complete genome and a closely related IdrA. Therefore, while there is poor conservation of genes surrounding $i d r A B P_{1} P_{2}$ and questions remain about its 
recent evolution, the high degree of conservation of $i d r A B P_{1} P_{2}$ locus itself and the phylogenetic pattern of inheritance support its description as an iodate reduction genomic island (IRI) that is subject to horizontal gene transfer. In addition to the perchlorate reduction genomic island (PRI) ${ }^{46}$ the IRI represents one of the few respiratory genomic islands known that crosses large phylogenetic boundaries (class, order, and family).

\section{Distribution of DIR populations in global oceans}

Many of the organisms with genes for DIR were identified in diverse marine habitats where $\mathrm{IO}_{3}{ }^{-}$ reduction is suspected to occur (Table 3). For example, Litorimicrobium taeanense is an aerobic, non-motile, Alphaproteobacterium isolated from a sandy beach in Taean, South Korea ${ }^{53}$. Other organisms such as Endozoicomonas sp. OPT23 and Litoreibacter ascidiaceicola were isolated from marine animals such as the intertidal marine sponge (Ophlitaspongia papilla) and the sea squirt (Halocynthia aurantium), respectively ${ }^{54,55}$. Additionally, organisms known to accumulate iodine, such as algae ${ }^{56}$ are associated with these bacteria as is the case with the bacterium Rhodophyticola porphyridii and the red algae Porphyridium marinum ${ }^{57}$. To investigate this marine prevalence further we used the $i d r A$ subunit as a marker gene to determine DIRM distribution across the Tara Oceans metagenome dataset. Our approach also identified the read abundance mapping to these unique IdrA hits at the different sites by using the transcripts per million (TPM) method for read quantification ${ }^{58,59}$. With this method, the number of unique IdrA hits was directly proportional to the number of reads mapped to the hits (Figure 6A and 6B). In general, locations with few unique IdrA hits lacked reads mapping to IdrA (Figure 6B). We observed that 77\% $(74 / 96)$ of the hits arose from the mesopelagic zone at an average depth of about 461 meters (range $270 \mathrm{~m}-800 \mathrm{~m}$ ) across identified stations (Figure S2). The remaining hits arose predominantly in epipelagic zones, such as the deep chlorophyll maximum in $21 \%$ of cases (20/96) and far fewer hits were observed in the mixed layer (1/96) or the surface water layer (1/96).

Although the presence of $i d r A$ exhibited some variability in depth, a geochemical feature common to all these hits was low oxygen concentrations. The vast majority of hits mapped to welldocumented oxygen minimal zones in the Arabian Sea ${ }^{60,61}$ and the Eastern Tropical Pacific ${ }^{62-64}$. Similarly, the North Pacific Subtropical and Polar Front (MRGID:21484) and the North Pacific Equatorial Countercurrent provinces (MRGID:21488) are two Longhurst provinces with OMZs that stand out in the Western hemisphere. At each of these locations, the median dissolved oxygen concentration at $i d r A$ positive locations was consistently lower than the dissolved oxygen concentrations at $i d r A$ absent locations $(65.24 \mu \mathrm{mol} / \mathrm{kg}$ versus $190.41 \mu \mathrm{mol} / \mathrm{kg}$; Figure $6 \mathrm{E})$. Among locations containing more than one $i d r A$ hit, the average oxygen concentration was about six times lower $(11.03 \mu \mathrm{mol} / \mathrm{kg})$; however, this average was skewed upward due to one outlier condition with $18 \mathrm{idrA}$ hits (Cumulative TPM of 89.30; Figure S2) occurring at a dissolved oxygen concentration of $95.4 \mu \mathrm{mol} / \mathrm{kg}$ (TARA_137_DCM_0.22-3). Environments meeting these conditions were the most common in mesopelagic zones broadly. One notable exception were the multiple hits at the deep chlorophyll maximum (DCM) at station 137. However, further inspection of the physical environment at the DCM revealed that this station matched mesopelagic environments more closely than surface waters or deep chlorophyll maxima. Research from Farrenkopf et al. indicated that bacteria are responsible for $\mathrm{IO}_{3}{ }^{-}$reduction in oxygen minimum zones $^{12,65}$. Further, Saunders et al. showed a preferential expression of AioA-like genes in the 
Eastern Pacific oxygen minimum zones, which our evidence now suggests are $\mathrm{IO}_{3}{ }^{-}$-reductases $294(\operatorname{IdrA})^{30}$.

To test whether locations with $i d r A$ possessed a unique chemical signature, we ran a principal component analysis using the variables associated with sample environments. Together the first two components of these geochemical variables explained $70.66 \%$ of the variance observed between $i d r A$ present and $i d r A$ absent samples. We determined that $i d r A$ presence was correlated most strongly with increased nitrate, phosphate, and silicate concentrations (Figure 6C-E). Additionally, $i d r A$ presence was negatively correlated with dissolved oxygen concentrations (Figure 6C-E). Such an observation is atypical for highly productive nitrate and phosphate depleted $\mathrm{OMZs}^{60,66,67}$. A possible explanation for this observation is that DIRM inhabit a unique niche above OMZs where residual $\mathrm{O}_{2}$ prevents $f n r$-dependent expression of nitrate reductase ${ }^{68}$. Organisms in these environments could potentially use $\mathrm{IO}_{3}{ }^{-}$as an alternative electron acceptor. Excess phosphorous in these zones seemingly serves as a proxy indicator of lower overall productivity, and potentially reflects the limiting concentration of $\mathrm{IO}_{3}{ }^{-}$and oxygen for biomass accumilation $^{4,23}$. Our explanation corroborates results from Farrenkopf et al. that shows an $\mathrm{I}^{-}$ maximum occurring at the boundary of the $\mathrm{OMZ}^{61}$, but further studies into the biochemistry of $\mathrm{IO}_{3}{ }^{-}$reduction under suboxic conditions and the contribution of DIRM to $\mathrm{I}^{-}$formation at this transition zone are necessary to undeniably link the $\mathrm{I}^{-}$maximum with the presence of $i d r A$ directly.

\section{Significance}

Here we describe a new organism, Denitromonas iodocrescerans, that grows by $\mathrm{IO}_{3}{ }^{-}$respiration which is mediated by a novel molybdenum dependent DMSO reductase. The conserved core genes associated with DIR and the chemistry of iodine oxyanions are consistent with a hybrid enzymaticabiotic pathway by which $\mathrm{IdrAB}$ reduces $\mathrm{IO}_{3}{ }^{-}$to $\mathrm{HIO}$, which abiotically disproportionates to $\mathrm{I}^{-}$and $\mathrm{IO}_{3}{ }^{-16,37}$. In this model, cytochrome c peroxidase like proteins ( $\operatorname{IdrP}_{1}$ and $\mathrm{IdrP}_{2}$ ) detoxify reactive $\mathrm{H}_{2} \mathrm{O}_{2}$ byproducts. Genes for this metabolism are part of a highly conserved $\mathrm{IO}_{3}{ }^{-}$reduction genomic island (IRI). Organisms harboring the IRI belong to phylogenetically distinct taxa, many of which are associated with marine sediments or multicellular hosts, suggesting that DIR is a horizontally transferred metabolism across marine ecosystems over geologic time. The abundance of IdrA genes across ocean metagenomes strongly correlates to oxygen minimum zones, indicating a niche for this metabolism in low-oxygen, high nitrate habitats across the ocean, from sediments to oxygen-minimum zones to the surfaces of multicellular organisms. In high-nitrate, low-oxygen conditions, bacteria with the IRI can use $\mathrm{IO}_{3}{ }^{-}$as an electron acceptor to obtain energy from the oxidation of organic matter. $\mathrm{IO}_{3}^{-}$is constantly replenished by the chemical oxidation of $\mathrm{I}^{-}$, so DIRM do not rely on other organisms for their substrate. $\mathrm{IO}_{3}^{-}$is typically scarce $(0.45 \mu \mathrm{M} \text { in seawater })^{4}$, so DIRM must compete with $\mathrm{IO}_{3}{ }^{-}$reduction by chemical reductants and by inadvertent biological activity, such as by algae, that contribute to the relative depletion of $\mathrm{IO}_{3}{ }^{-}$in those waters ${ }^{7,61,65,69,70}$. By analogy, perchlorate-reducing bacteria, which are common but sparse due to low natural abundance of perchlorate ${ }^{71}$, may provide further insight into the ecology of DIRM broadly. The rarity of $\mathrm{IO}_{3}{ }^{-}$reduction genes among bacteria despite the ability of the metabolism to be horizontally transferred likely reflects the evolutionary constrains of growth by DIR. Intriguingly, one organism, Sedimenticola thiotaurini, seemingly possesses both perchlorate and $\mathrm{IO}_{3}{ }^{-}$reduction pathways, presenting future opportunities to study the ecology of these metabolically versatile 
microorganisms ${ }^{72}$. Moreover, organisms such as Vibrio spp. and Moritella spp. show some degree of vertical transfer for the IRI throughout recent evolutionary history, indicating possible niches among sea fauna and cold environments where DIR is biogeochemically favorable. Future studies addressing the affinity of $\mathrm{IdrAB}$ for $\mathrm{IO}_{3}{ }^{-}$may also shed light on how DIRM thrive at such low environmental concentrations. Additionally, further research into the chemistry of iodine oxyanions may provide insight on the intermediates of $\mathrm{IO}_{3}{ }^{-}$reduction. Addressing these open questions may ultimately shed light on new potential niches for DIRM and provide a role for these organisms in potentiating iodine redox cycling globally.

\section{Description and Phylogeny of Denitromonas iodocrescerans sp. nov. strain IR-12 ${ }^{\mathrm{T}}$}

Denitromonas iodocrescerans (i.o.do.cre'scer.ans) Chem. n. iodo as it pertains to iodine; L. pres. part. crescerans for growing; N.L. pres. part. iodocrescerans iodine-growing.

D. iodocrescerans is a facultatively anaerobic chemoorganotroph, gram negative, rod-shaped, 1.5$2.0 \mu \mathrm{M}$ long by $0.6-0.7 \mu \mathrm{M}$ wide, and motile by means of a unipolar flagellum (Figure 1B). Colonies are circular, smooth, and range in color from transparent to an opaque/whitish-sky blue color after 48 hours of growth on R2A agar at $30^{\circ} \mathrm{C}$. Extended growth on R2A agar (96 or more hours) results in a light coral pink colony color. D. iodocrescerans grows by oxidizing D-glucose, lactate, or acetate with concomitant reduction of oxygen $\left(\mathrm{O}_{2}\right)$, nitrate $\left(\mathrm{NO}_{3}^{-}\right)$, or iodate $\left(\mathrm{IO}_{3}^{-}\right)$. It grows on up to $4 \mathrm{mM}$ of iodate with an optimum at $2 \mathrm{mM}$. Additionally, the organism can tolerate up to $6.25 \mathrm{mM}$ of iodide. Growth occurs between $20-30^{\circ} \mathrm{C}$ with an optimum of $30^{\circ} \mathrm{C}$. It grows at a range of $0-5 \%$ salinity with an optimum of $3 \% \mathrm{NaCl}$ on minimal media. D. iodocrescerans has an innate resistance to tetracycline $(10 \mu \mathrm{g} / \mu \mathrm{L})$ and chloramphenicol $(25 \mu \mathrm{g} / \mu \mathrm{L})$ but is sensitive to kanamycin, which inhibits growth at concentrations as low as $5 \mu \mathrm{g} / \mu \mathrm{L}$.

The genome of $D$. iodocrescerans is $5,181,847$ bp (average coverage 64.2x) with 4697 CDS, a $\mathrm{G}+\mathrm{C}$ content of $66.54 \%, 57$ tRNAs, one tmRNA, one CRISPR, and a single plasmid 81,584 bp long whose function remains unclear. The full genome has been deposited in GenBank (BioProject ID PRJNA683738) currently consisting of 202 contigs. Phylogenetically, D. iodocrescerans belongs to the class Betaproteobacteria; however, its phylogeny beyond this class becomes less clear. The 16S rRNA locus suggests that D. iodocrescerans is a subclade of Azoarcus, which belongs to the family Zoogloeaceae ${ }^{73}$. However, the NCBI database suggests that the genus Denitromonas belongs to the family Rhodocyclaceae.

The type strain of Denitromonas iodocrescerans, IR-12 ${ }^{\mathrm{T}}$, was enriched from marine sediment from the Berkeley Marina in the San Francisco Bay during the Fall of 2018 (further details explained in methods below). The strain has been deposited in the American Type Culture Collection (ATCC XXXXX).

\section{Acknowledgements}

The authors acknowledge Mariana Shalit, Dylan Dang, Jessica Kretschmer, Rachael Peng, Mitchell Thompson, and Hans Carlson for lab support and advice throughout the project. Funding 
375 for research on iodate in the Coates lab was provided to VRU through the NSF GRFP Base Award: 376 DGE1752814.

\section{Conflict of Interest}

379

380

381

382

383

384

385

386

387

388

389

390

The authors declare that they have no conflict of interest with the research presented in this article.

\section{Contributions}

JDC guided the research. VRU and KL performed all physiology experiments and measurements. VRU performed all cloning experiments. VRU and TPB performed the comparative genomic analysis and phylogenetic analyses. VRU and ZH performed the analysis of the TARA Oceans data. VRU and JDC developed the model. VRU wrote the draft manuscript and created the figures with guidance from JDC. All authors contributed to data analysis, reviewed the manuscript, and approved of its publication.

\section{Methods}

$\underline{\text { Media, chemicals, and culture conditions }}$

Anaerobic enrichment cultures from marine environments were grown at $30^{\circ} \mathrm{C}$ using a minimal media containing the following per liter: $0.54 \mathrm{~g} \mathrm{NH} 4 \mathrm{Cl}, 0.14 \mathrm{~g} \mathrm{KH}_{2} \mathrm{PO}_{4}, 0.20 \mathrm{~g} \mathrm{MgCl}_{2} \cdot 6 \mathrm{H}_{2} \mathrm{O}$, $0.14 \mathrm{~g} \mathrm{Na}_{2} \mathrm{SO}_{4} \cdot 10 \mathrm{H}_{2} \mathrm{O}, 20.0 \mathrm{~g} \mathrm{NaCl}, 0.24 \mathrm{~g} \mathrm{Na} \mathrm{MoO}_{4} 0.20 \mathrm{~g}$, and 2.5g $\mathrm{NaHCO}_{3}$ with an added vitamin mix and mineral mix. Oxygen was removed from the media and bottles were dispensed in an $80 \% \mathrm{~N}_{2} / 20 \% \mathrm{CO}_{2}$ atmosphere. Anaerobic subcultures for isolation were grown in Artificial Pore Water (APM) medium at $30^{\circ} \mathrm{C}\left(30.8 \mathrm{~g} \mathrm{NaCl}, 1.0 \mathrm{~g} \mathrm{NH} 4 \mathrm{Cl}, 0.77 \mathrm{~g} \mathrm{KCl}, 0.1 \mathrm{~g} \mathrm{KH}_{2} \mathrm{PO}_{4}, 0.20 \mathrm{~g}\right.$ MgSO4·7H2O, $0.02 \mathrm{~g} \mathrm{CaCl}_{2} \cdot 2 \mathrm{H}_{2} \mathrm{O}, 7.16 \mathrm{~g}$ HEPES, along with vitamin and mineral mixes. A post sterile addition of $34.24 \mathrm{~mL} 0.4 \mathrm{M} \mathrm{CaCl} 2$ and $26.07 \mathrm{~mL} 2 \mathrm{M} \mathrm{MgCl}_{2} \cdot 6 \mathrm{H}_{2} \mathrm{O}$ was added to all APM media. Conditions with lactate, acetate, iodate, and nitrate all used the sodium salts of these compounds. Conditions without molybdenum omitted $\mathrm{Na}_{2} \mathrm{MoO}_{4}$ from the mineral mixes. Aerobic cultures were all grown either on APM, R2A (HiMedia, USA), or R2A agar (BD Biosciences, USA). Kanamycin concentrations when used were at one tenth the standard concentrations on plates ( $5 \mathrm{mg} / \mathrm{L}$, Sigma Aldrich, USA) and at one fourth the standard concentration in liquid (12.5 $\mathrm{mg} / \mathrm{L}$ ). All compounds were purchased through Sigma Aldrich (Sigma Aldrich, USA). Growth of tubes were measured either using the Thermo Scientific ${ }^{\text {TM }}$ GENESYS ${ }^{\text {TM }} 20$ or the TECAN Sunrise ${ }^{\text {TM }}$ 96-well microplate reader set at a wavelength of $600 \mathrm{~nm}$. For growth measurements in

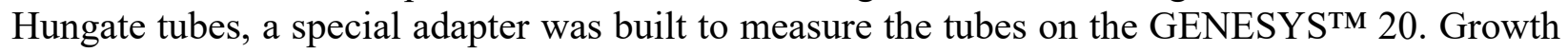
experiments using the microplate reader were run in an anerobic glove bag.

\section{$\underline{\text { Isolation of dissimilatory iodate-reducing bacteria }}$}


411 Sediment from the oxic/anoxic boundary layer in the San Francisco Bay estuary (3786'56.4" N, $\left.412-122^{\circ} 30^{\prime} 63.9^{\prime \prime} \mathrm{W}\right)$ was added to anaerobic media bottles at $25 \mathrm{~g} / 100 \mathrm{~mL}$ for isolation of 413 dissimilatory iodate-reducing bacteria. Samples were degassed and amended with acetate and 414 iodate to enable growth of heterotrophic iodate reducing bacteria. Enrichments that showed iodate reduction to iodide were then passaged at least five times into fresh minimal media with $10 \mathrm{mM}$ acetate and $2 \mathrm{mM}$ iodate. To ensure purity of the passaged enrichment culture, the organism was plated aerobically onto an agar plate containing the minimal media, and a single colony was

418 isolated from this plate.

$\underline{\text { Strains and plasmids }}$

All plasmids, primers and strains constructed are listed in Table S1. The E. coli strain used for plasmid propagation was XL1-Blue, while WM3064 was used to perform conjugations. Plasmid pNTPS138, a generous gift from the Kathleen Ryan Lab at UC Berkeley, was used for the SacB counterselection. Plasmid pBBR1-MCS2 is a low copy expression vector and was used for complementation experiments. All expression plasmids and deletion vectors were constructed using the Benchling software suite (San Francisco, USA). Plasmids were assembled either by Gibson assembly or restriction digestion and ligation using standard procedures. Gibson assembly was carried out using NEB HiFi 2x Master Mix, and remaining enzymes and master mixes were ordered from New England Biosciences (NEB, USA). Plasmids were routinely isolated using the Qiaprep Spin Miniprep kit (Qiagen, USA), and all primers were ordered from Integrated DNA Technologies (IDT, Coralville, IA). Amplification of DNA for generating assembly products was performed using Q5 DNA Polymerase 2x Master Mix (NEB, USA) with 3\% DMSO. Amplification of distinct portions of the genome were optimized since most sequences in the iodate reduction cluster contain at minimum $60 \%$ GC content, making amplification relatively challenging. All D. iodocrescerans strains (pre- or post-transformation) were propagated from glycerol stocks $(25 \%$ glycerol $)$ stored at $-80^{\circ} \mathrm{C}$, grown on a plate for up to 72 hours, picked and then grown for an additional 48-72 hours in liquid R2A. For additional information on performing transformations and conjugations in D. iodocrescerans see supplemental methods.

A Dionex ${ }^{\mathrm{TM}}$ IonPac ${ }^{\mathrm{TM}}$ AS25 Anion Exchange Column (Thermo Fischer, USA) was used exclusively to measure the consumption of iodate and acetate, as well as the production of iodide in all samples. Briefly, all samples are diluted 1:25 in deionized water and loaded onto the autosampler for processing. Standards are made by serial dilution starting with $1 \mathrm{mM}$ of the standard molecule. All samples were run in triplicate. Acetate peaks were consistently detected at 3.6 minutes, iodate peaks were consistently detected at 3.8 minutes, and iodide peaks were consistently detected at 11.5 minutes at a flow rate of $1 \mathrm{~mL} / \mathrm{min}$.

\section{Genome sequencing, comparative genomics, and phylogenetic analysis}

447 Genome sequencing was carried out on an Illumina HiSeq4000 using 150bp paired end reads. The 448 genome was subsequently assembled using SPAdes $3.9^{74}$ and the assembly graph was assessed for completion using bandage ${ }^{75}$. The Prokka (version 1.14) pipeline was then used to generate the genome annotations and the general feature format file (.gff), which allowed for genome navigation and visualization on the Artemis software (available at http://sanger- 
pathogens.github.io $)^{76}$. To search for the iodate reduction island, MMseqs2 was used to cluster homologous proteins in the amino acid FASTA (.faa) files from D. iodocrescerans, $P$. stutzeri sp. SCT, D. halophilus SFB-1, and $P$. stutzeri sp. CAL by subfamily ${ }^{41}$. A presence and absence matrix for each subfamily was generated and represented as a four-way Venn diagram using pyvenn (https://github.com/tctianchi/pyvenn). To identify additional iodate reductase proteins in public databases, a profile-HMM was constructed using HMMER 3.0 following a multiple sequence alignment using MUSCLE 3.8 on the molybdopterin oxidoreductase (Pfam_00384) seed set and $D$. iodocrescerans $/ P$. stutzeri SCT IdrA proteins ${ }^{77,78}$. A separate arsenite oxidase (AioA) profileHMM was created using analogous methods. Genomes from high probability HMM hits (threshold above 640 on https://www.ebi.ac.uk/Tools/hmmer/search/phmmer) and BLAST hits were downloaded from NCBI using ncbi-genome-download (https://github.com/kblin/ncbi-genomedownload). Approximately-maximum-likelihood phylogenetic trees were generated using Fasttree $^{79}$ specifying 10,000 resamples and using standard settings for everything else. Visualization of resultant trees used the ete 3 toolkit ${ }^{80}$. To perform the neighborhood frequency analysis, 10 genes upstream and downstream from the aio $A$ or $i d r A$ locus were extracted from the associated GenBank files for each genome, and MMseqs2 was used to cluster homologous proteins into subfamilies ${ }^{41}$. To search for cld in the downloaded genomes, a profile-HMM for cld, described previously, was used ${ }^{81}$. Frequency was calculated as number of genomes in possession of a cluster divided by the total number of genomes. Projections of this data were drawn using a custom Python 3.7 script. All tanglegram analyses used Dendroscope to load trees for processing and visualization ${ }^{47}$.

Distribution of iodate reductase in ocean metagenomes

\section{4}

475

476
The profile-HMM for iodate reductase (described above) was used to search all 40 million nonredundant open reading frames from the 243-sample Tara oceans dataset. Open reading frames were downloaded (available from https://www.ebi.ac.uk/ena/data/view/PRJEB7988) and translated to amino acid sequences using custom BioPython code ${ }^{82,83,84}$. The amino acid sequences in the 0.22-micron and 0.45-micron range were then searched for hits using the IdrA profile-HMM set at a threshold score of 640 . Hits were then grouped by station for further analysis. Reads were mapped to scaffolds with Bowtie $2^{85}$ and reads were counted using SAMtools ${ }^{86}$. Read abundance mapping to these unique IdrA hits were quantified by using the transcripts per million (TPM) method for read quantification as described in Ribicic et a ${ }^{58,59}$. Ten variables in the metadata associated with the chemical environment at each sampling location were analyzed using the principal component analysis module on scikit-learn $0.23 .1^{87}$. All sites regardless of $i d r A$ presence were included in the analysis. Missing metadata values were imputed using the Multivariate Imputation by Chained Equations method (MICE) ${ }^{88}$. Variables included in the analysis were 'Sampling depth [m]', 'Mean_Temperature [deg C]', 'Mean_Salinity [PSU]','Mean_Oxygen [umol/kg]', 'Mean_Nitrates[umol/L]', 'NO2 [umol/L]', 'PO4 [umol/L]', 'SI [umol/L]','NO2NO3 [umol/L]', and irradiance 'AMODIS:PAR8d,Einsteins/m-2/d-1'. Components were built using "pca.fit_transform()" and confidence ellipses at one standard deviation were set for each group. Component coefficients were extracted from principal components by using "pca.components_" and displayed as a loadings plot. Explained variance was also extracted from "pca.components_" to display on PCA axes. The map of $i d r A$ abundance was created using Cartopy 0.17. 


\section{Figure legends.}

Figure 1: Phylogeny and Physiology of Denitromonas iodocrescerans. A) 16S rRNA gene phylogeny of Denitromonas iodocrescerans (denoted by a purple star) belonging to a subclade of Azoarcus, separate from other known Azoarcus species. B) TEM images of an active culture of $D$. iodocrescerans with the scale at $2 \mu \mathrm{m}$ (left) and $0.2 \mu \mathrm{m}$ (right) taken on a Technai 12 TEM. C) Iodate consumption ( $\boldsymbol{\square})$, acetate consumption $(\boldsymbol{\Delta})$, iodide production $(\boldsymbol{\square})$, and growth ( $\bullet$; measured as optical density at $\lambda=600 \mathrm{~nm}$; OD600) in an active culture of $D$. iodocrescerans growing anaerobically. $\mathrm{N}=3$ and error bars show standard deviation. D) Iodate consumption across all five conditions assessed in the growth experiment in $\mathrm{C}$. $\mathrm{N}=3$ and error bars show standard deviation.

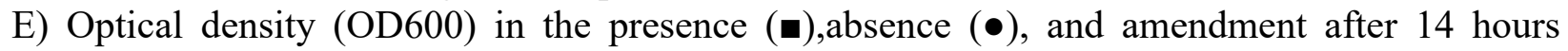
incubation $(\boldsymbol{\Delta})$ of $\mathrm{MoO}_{4}{ }^{2-}$. $\mathrm{N}=7$ and error bars show standard deviation.

Figure 2: Identification of unique gene cluster in iodate reducing genomes enablling the identification and characterization of the iodate reductase (IdrA). A) A four-way comparison between two genomes from confirmed DIRM (solid line) and two genomes from closely related non-DIRM (dotted line) identifying 26 shared genes among the two taxonomically distinct iodate reducing bacteria (Table S2). B) The three genes upstream of the predicted molybdopterin oxidoreductase (IdrA) involved in DIR. C) anaerobic growth of wildtype of D. iodocrescerans in the presence $(\bullet)$ or absence ( () of iodate in comparison to the $\Delta i d r A$ mutant $(\triangle)$ or the $\Delta i d r A$ mutant complemented with an empty vector $(\Delta)$ or with idrA in trans $(\mathbf{\square}) . \mathrm{N}=8$ and error bars represent standard deviation.

Figure 3 Mechanistic and Ecological Models of Iodate Reduction. A) A representation of the electron flow (black arrows) from the quinone pool to iodate in D. iodocrescerans. Abbreviations: $\mathrm{QH}_{2}$-reduced quinone, $\mathrm{Q}$-oxidized quinone, bc1-bc1 complex, $\mathrm{IO}_{3}$ - iodate, $\mathrm{HIO}$ hypoiodous acid, I-iodide. Gray arrows represent micromolar production of yet unknown oxidant that is detoxified by $\operatorname{IdrP}_{1}$ and $\mathrm{IdrP}_{2}$. B) Ecological model of iodate reducing bacteria. Top right panel represents locations in the open ocean near oxygen minimum zones inhabited by DIORM. Bottom right panel represents host associated DIORM. DOM-dissolved organic matter.

Figure 4 Phylogeny and Taxonomic Distribution of IdrA. A) Phylogeny of Molybdopterin Oxidoreductases (Pfam 00384) using pre-aligned proteins from the representative proteomes 55 dataset. Green bars indicate location of an individual protein in each branch belonging to the labelled group. B) Phylogeny of IdrA (purple), AioA (gray), and an unknown clade (light green) that contains proteins from organisms showing demonstrated arsenite oxidation abilities. Colored circles along the edges of the IdrA clade indicate the different Phyla each organism belongs to.

Figure 5 Phylogeny and Gene Neighborhoods of arsenite oxidase, iodate reductase, and the associated unknown clade. A pruned tree of the molybdopterin oxidoreductase phylogeny (left) showing a representative subset of genomes identified from Figure 3B. Denitromonas iodocrescerans is illustrated in bold. Genome neighborhoods (right) show 10 genes upstream and downstream (if present) from the idrA locus. Individual genes were clustered into groups based on amino acid similarity using MMSeqs 2 and the frequency of genomes possessing an individual cluster is colored by the intensity of purple. Circles above each gene represents either the 
molybdopterin oxidoreductase $(\bullet)$, the associated Rieske containing subunit $(\bullet)$, or the di-haem cytochrome c peroxidases $(\bullet)$.

Figure 6 Analysis of Tara Oceans dataset identifies possible ecological niche above oxygen minimum zones. A) A map indicating sampled locations during the Tara expedition $(\mathrm{x})$ alongside sampling locations with IdrA present (purple circles). Markers overlaid directly on top of each other demonstrate transect samples from different depths at a given location. Size of purple circle shows the cumulative TPM at a particular site. B) Chart on the left shows the TPM of individual hits on a scaffold organized by Tara location identifier. Coloration represents the individual Tara station while marker shape indicates general geographic location. Chart on the right correlates the number of unique IdrA hits at any given site to the cumulative TPM at an individual location. Tara station is denoted by color and general geographic location is denoted by marker shape. C) A principal component analysis displaying the first two principal components. Locations are grouped by IdrA absent (x), presence of a single IdrA hit ( $\square)$, or presence of multiple hits ( $\square$ ). Ellipses represent 1 standard deviation of the mean. The color of the ellipse corresponds to the variable grouping. D) A loading plot of the ten variables used in the first two principal components with variables identified at the end of each arrow. E) The means of select environmental variables at IdrA present sites (purple) and IdrA absent sites (gray). Error bars indicate 95\% confidence interval. Units for each of the variables are located near the variable name. 


\section{References}

5631 Carpenter, L. J. in Encyclopedia of Atmospheric Sciences 205-219 (Elsevier, 2015).

5642 Chemburkar, S. R., Deming, K. C. \& Reddy, R. E. Chemistry of thyroxine: an historical perspective and recent progress on its synthesis. Tetrahedron 66, 1955-1962, doi:10.1016/J.TET.2009.12.044

566 (2010).

Schweizer, U. \& Steegborn, C. Thyroid hormones-From crystal packing to activity to reactivity. Angew. Chem 54, 12856-12858, doi:10.1002/anie.201506919 (2015). (2011).

5 Manley, S. L. \& Dastoor, M. N. Methyl iodide ( $\mathrm{CH} 3 \mathrm{I})$ production by kelp and associated microbes.

573 Marine Biol 98, 477-482, doi:10.1007/BF00391538 (1988). ichi nuclear accident. J Environ Radioact 151, 82-93, doi:10.1016/j.jenvrad.2015.06.001 (2016). Orbital Theory Considerations. Aquat Chem Adv, doi:10.1021/ba-1995-0244.ch006 (1995). forests on iodine speciation in coastal seawater. PLOS ONE 12, e0180755, doi:10.1371/journal.pone.0180755 (2017).

Tsunogai, S. \& Sase, T. Formation of iodide-iodine in the ocean. Deep Sea Research and

Youngblut, M. D. et al. Perchlorate Reductase Is Distinguished by Active Site Aromatic Gate Residues. J Biol Chem 291, 9190-9202, doi:10.1074/jbc.M116.714618 (2016).

Farrenkopf Ay, A. M. et al. Reduction of iodate in seawater during Arabian Sea incubations and in laboratory cultures of the marine Shewanella putrefaciens strain MR-4 shipboard bacterium. 2920.14988 (2020). 
59615 Youngblut, M. D., Wang, O., Barnum, T. P. \& Coates, J. D. (Per)chlorate in biology on earth and 597 beyond. Ann rev Microbiol 70, 435-457, doi:10.1146/annurev-micro-102215-095406 (2016).

$598 \quad 16 \quad$ WHO. Alternative drinking-water disinfectants. 52-55 (2018).

59917 Haimovich, O. \& Treinin, A. Disproportionation of hypoiodite. J Phys Chem 71, 1941-1943, $600 \quad$ doi:10.1021/j100865a068 (1967).

60118 Toporek, Y. J. et al. Metal reduction and protein secretion genes required for iodate reduction by 602 Shewanella oneidensis. Appl Environ Microbiol 85, doi:10.1128/aem.02115-18 (2019).

60319 Carlström, C. I. et al. Characterization of an anaerobic marine microbial community exposed to 604 combined fluxes of perchlorate and salinity. Appl Microbiol Biotechnol 100, 9719-9732, 605 doi:10.1007/s00253-016-7780-5 (2016).

60620 Yip, K. C.-W. \& Gu, J.-D. A novel bacterium involved in the degradation of 2-methylindole isolated 607 from sediment of Inner Deep Bay of Hong Kong. Appl Environ Biotechnol 1, 52-63 (2015). Escherichia coli in a rocking-motion-type bioreactor. Microb Cell Fact 9, 42, doi:10.1186/14752859-9-42 (2010).

61423 McInerney, M. J. \& Beaty, P. S. Anaerobic community structure from a nonequilibrium 615 Loferer-Krössbacher, M., Klima, J. \& Psenner, R. Determination of bacterial cell dry mass by transmission electron microscopy and densitometric image analysis. Appl Environ Microbiol 64, 688-694, doi:10.1128/aem.64.2.688-694.1998 (1998).

61624 Stern, J. H. \& Passchier, A. A. The heats of formation of triiodide and iodate ions. J Phys Chem 66, 617 752-753, doi:10.1021/j100810a041 (1962).

61825 Weber, K. A., Achenbach, L. A. \& Coates, J. D. Microorganisms pumping iron: anaerobic microbial 619 iron oxidation and reduction. Nat Rev Microbio/ 4, 752-764, doi:10.1038/nrmicro1490 (2006).

62026 Leimkühler, S. \& lobbi-Nivol, C. Bacterial molybdoenzymes: old enzymes for new purposes. FEMS 621 Microbiol Rev 40, 1-18, doi:10.1093/femsre/fuv043 (2016).

62227 McEwan, A. G., Ridge, J. P., McDevitt, C. A. \& Hugenholtz, P. The DMSO reductase family of microbial molybdenum enzymes; molecular properties and role in the dissimilatory reduction of toxic elements. Geomicrobiol J 19, 3-21, doi:10.1080/014904502317246138 (2002). doi:10.1128/aem.68.9.4425-4430.2002 (2002).

62829 Snel, B., Bork, P. \& Huynen, M. A. Genomes in flux: the evolution of archaeal and proteobacterial 629 gene content. Gen Res 12, 17-25 (2002). 
63030 Saunders, J. K., Fuchsman, C. A., McKay, C. \& Rocap, G. Complete arsenic-based respiratory cycle 631 in the marine microbial communities of pelagic oxygen-deficient zones. Proc Nat Acad Sci, 201818349, doi:10.1073/pnas.1818349116 (2019).

63331 Dabir, D. V. et al. A role for cytochrome $\mathrm{c}$ and cytochrome c peroxidase in electron shuttling from 634 Erv1. EMBO J 26, 4801-4811 (2007).

63532 Martins, D., Kathiresan, M. \& English, A. M. Cytochrome c peroxidase is a mitochondrial heme636 based H2O2 sensor that modulates antioxidant defense. Free Rad Bio Med 65, 541-551 (2013).

63733 Almagro Armenteros, J. J. et al. SignalP 5.0 improves signal peptide predictions using deep neural networks. Nat Biotechnol 37, 420-423, doi:10.1038/s41587-019-0036-z (2019).

63934 Berks, B. C. The Twin-Arginine Protein Translocation Pathway. Annl Rev Biochem 84, 843-864, 640 doi:10.1146/annurev-biochem-060614-034251 (2015).

64135 Toporek, M., Michałowska-Kaczmarczyk, A. M. \& Michałowski, T. Disproportionation reactions of 642 HIO and NalO in static and dynamic systems. Am J Anal Chem 5, 1046 (2014).

Youngblut, M. D. et al. Perchlorate reductase is distinguished by active site aromatic gate residues. J Biol Chem 291, 9190-9202, doi:10.1074/jbc.M116.714618 (2016). 671-676, doi:https://doi.org/10.1016/0043-1354(89)90198-X (1989). 85-87 (2013). reducing bacterium. Wat Res 42, 2403-2410, doi:https://doi.org/10.1016/j.watres.2008.01.009 (2008).

Steinegger, M. \& Söding, J. MMseqs2 enables sensitive protein sequence searching for the analysis of massive data sets. Nat Biotechno/ 35, 1026-1028, doi:10.1038/nbt.3988 (2017). doi:10.1007/s00248-018-1159-3 (2018). 
$66545 \mathrm{He}, \mathrm{Z}$. et al. A novel denitrifying methanotroph of the NC10 phylum and its microcolony. Sci Rep $666 \quad$ 6, 32241, doi:10.1038/srep32241 (2016).

$66746 \quad$ Melnyk, R. A. et al. Identification of a perchlorate reduction genomic island with novel regulatory 668 and metabolic genes. Appl Environ Microbiol 77, 7401-7404, doi:10.1128/AEM.05758-11 (2011).

66947 Scornavacca, C., Zickmann, F. \& Huson, D. H. Tanglegrams for rooted phylogenetic trees and 670 networks. Bioinformatics (Oxford, England) 27, i248-i256, doi:10.1093/bioinformatics/btr210 $671 \quad$ (2011).

67248 Juhas, M. et al. Genomic islands: tools of bacterial horizontal gene transfer and evolution. FEMS 673 Microbiol Rev 33, 376-393, doi:10.1111/j.1574-6976.2008.00136.x (2009).

67449 Reiter, W. D., Palm, P. \& Yeats, S. Transfer RNA genes frequently serve as integration sites for 675

50 Larbig, K. D. et al. Gene islands integrated into tRNAGly genes confer genome diversity on a Pseudomonas aeruginosa clone. J Bacteriol 184, 6665, doi:10.1128/JB.184.23.6665-6680.2002 678 (2002).

51 Boyd, E. \& Barkay, T. The mercury resistance operon: from an origin in a geothermal environment 680 to an efficient detoxification machine. Front Microbiol 3, doi:10.3389/fmicb.2012.00349 (2012).

68152 Besaury, L. et al. Abundance and diversity of copper resistance genes cusA and copA in microbial 682 communities in relation to the impact of copper on Chilean marine sediments. Mar Pollut Bull 67, 16-25, doi:https://doi.org/10.1016/j.marpolbul.2012.12.007 (2013).

53 Jin, H. M. et al. Litorimicrobium taeanense gen. nov., sp. nov., isolated from a sandy beach. International J Sys Evol Microbiol 61, 1392-1396, doi:https://doi.org/10.1099/ijs.0.025007-0 (2011). isolated from a marine sponge and the genomic repertoire for host-bacteria symbioses. Microorganisms 7, 635 (2019).

Kim, Y.-O. et al. Litoreibacterascidiaceicola sp. nov., isolated from the golden sea squirt Halocynthiaaurantium. Int J Sys Evol Microbiol 64, 2545-2550, doi:https://doi.org/10.1099/ijs.0.064196-0 (2014). atmospheric chemistry. Proc Nat Acad Sci 105, 6954-6958, doi:10.1073/pnas.0709959105 (2008). doi:https://doi.org/10.1099/ijsem.0.003371 (2019).

69858 Wagner, G. P., Kin, K. \& Lynch, V. J. Measurement of mRNA abundance using RNA-seq data: RPKM 
59 Ribicic, D. et al. Microbial community and metagenome dynamics during biodegradation of dispersed oil reveals potential key-players in cold Norwegian seawater. Mar Pollut Bull 129, 370378, doi:https://doi.org/10.1016/i.marpolbul.2018.02.034 (2018).

60 Lachkar, Z., Lévy, M. \& Smith, K. S. Strong intensification of the Arabian Sea oxygen minimum zone in response to Arabian Gulf warming. Geophys Res Lett 46, 5420-5429, doi:10.1029/2018gl081631 (2019).

61 Farrenkopf, A. M. \& lii, G. W. L. lodine chemistry reflects productivity and denitrification in the Arabian Sea: evidence for flux of dissolved species from sediments of western India into the OMZ. Deep-Sea Res I/ 49, 2303-2318 (2002).

62 Bertagnolli, A. D. \& Stewart, F. J. Microbial niches in marine oxygen minimum zones. Nat Rev Microbiol 16, 723-729, doi:10.1038/s41579-018-0087-z (2018).

63 Cutter, G. A., Moffett, J. W., Nielsdóttir, M. C. \& Sanial, V. Multiple oxidation state trace elements in suboxic waters off Peru: In situ redox processes and advective/diffusive horizontal transport. Mar Chem 201, 77-89, doi:10.1016/J.MARCHEM.2018.01.003 (2018).

64 Karstensen, J., Stramma, L. \& Visbeck, M. Oxygen minimum zones in the eastern tropical Atlantic and Pacific oceans. Prog Ocean 77, 331-350, doi:https://doi.org/10.1016/i.pocean.2007.05.009 (2008).

65 Farrenkopf, A. M., Luther, G. W., Truesdale, V. W. \& Van Der Weijden, C. H. Sub-surface iodide maxima: evidence for biologically catalyzed redox cycling in Arabian Sea OMZ during the SW intermonsoon. Deep Sea Res Part II: Topical Studies in Oceanography 44, 1391-1409, doi:https://doi.org/10.1016/S0967-0645(97)00013-1 (1997).

66 Kalvelage, T. et al. Aerobic microbial respiration in oceanic oxygen minimum zones. PloS one 10, e0133526-e0133526, doi:10.1371/journal.pone.0133526 (2015).

67 Howarth, R. W. Nutrient limitation of net primary production in marine ecosystems. Ann Rev Ecol Sys 19, 89-110 (1988).

68 Shalel Levanon, S., San, K.-Y. \& Bennett, G. N. Effect of oxygen on the Escherichia coli ArcA and FNR regulation systems and metabolic responses. Biotech Bioeng 89, 556-564, doi:10.1002/bit.20381 (2005).

Wadley, M. R. et al. Modelling iodine in the ocean. (2020).

Waite, T. J. \& Truesdale, V. W. lodate reduction by Isochrysis galbana is relatively insensitive to de-activation of nitrate reductase activity-are phytoplankton really responsible for iodate reduction in seawater? Mar Chem 81, 137-148, doi:10.1016/S0304-4203(03)00013-6 (2003).

Coates, J. D. \& Achenbach, L. A. Microbial perchlorate reduction: rocket-fuelled metabolism. Nat Rev Microbiol 2, 569-580, doi:10.1038/nrmicro926 (2004).

72 Jones, D. S., Bailey, J. V. \& Flood, B. E. Sedimenticola thiotaurini sp. nov., a sulfur-oxidizing bacterium isolated from salt marsh sediments, and emended descriptions of the genus 
Sedimenticola and Sedimenticola selenatireducens. Int J Sys Evol Microbiol 65, 2522-2530, doi:10.1099/ijs.0.000295 (2015).

Boden, R., Hutt, L. P. \& Rae, A. W. Reclassification of Thiobacillus aquaesulis (Wood \& Kelly, 1995) as Annwoodia aquaesulis gen. nov., comb. nov., transfer of Thiobacillus (Beijerinck, 1904) from the Hydrogenophilales to the Nitrosomonadales, proposal of Hydrogenophilalia class. nov. within the 'Proteobacteria', and four new families within the orders Nitrosomonadales and Rhodocyclales. Int J Sys Evol Microbiol 67, 1191-1205, doi:https://doi.org/10.1099/ijsem.0.001927 (2017).

74 Bankevich, A. et al. SPAdes: a new genome assembly algorithm and its applications to single-cell sequencing. J Comput Biol 19, 455-477, doi:10.1089/cmb.2012.0021 (2012). genome assemblies. Bioinformatics 31, 3350-3352, doi:10.1093/bioinformatics/btv383 (2015). doi:10.1093/bioinformatics/btu153 (2014).

Edgar, R. C. MUSCLE: multiple sequence alignment with high accuracy and high throughput. Nucl Acid Res 32, 1792-1797, doi:10.1093/nar/gkh340 (2004).

Price, M. N., Dehal, P. S. \& Arkin, A. P. FastTree 2--approximately maximum-likelihood trees for interactions, and unexpected diversity in perch

Cock, P. J. et al. Biopython: freely available Python tools for computational molecular biology and bioinformatics. Bioinformatics 25, 1422-1423 (2009). 
$771 \quad 87$

772

773

774

775

776

777

778

779

780

781

782

783

784

785

786

787

788

789

790

791

792

793

794

795

796

797

798

799

800

$801 \quad 97$

802

803

804

805

806

807

Pedregosa, F. et al. Scikit-learn: Machine learning in Python. J Mach Learn Res 12, 2825-2830 (2011).

88 Azur, M. J., Stuart, E. A., Frangakis, C. \& Leaf, P. J. Multiple imputation by chained equations: what is it and how does it work? Int J Methods Psychiatr Res 20, 40-49, doi:10.1002/mpr.329 (2011).

89 Chao, L. S.-L., Davis, R. E. \& Moyer, C. L. Characterization of bacterial community structure in vestimentiferan tubeworm Ridgeia piscesae trophosomes. Mar Ecol 28, 72-85, doi:https://doi.org/10.1111/i.1439-0485.2007.00151.x (2007).

90 Patra, A. K. et al. Phylogenetic relationship between symbionts of tubeworm Lamellibrachia satsuma and the sediment microbial community in Kagoshima Bay. Ocean Sci J 51, 317-332, doi:10.1007/s12601-016-0028-6 (2016).

91 Gardebrecht, A. et al. Physiological homogeneity among the endosymbionts of Riftia pachyptila and Tevnia jerichonana revealed by proteogenomics. ISME J 6, 766-776, doi:10.1038/ismej.2011.137 (2012).

92 Wang, Z. et al. Alginatibacterium sediminis gen. nov., sp. nov., a novel marine gammaproteobacterium isolated from coastal sediment. Int J Sys Evol Microbiol 69, 511-516, doi:https://doi.org/10.1099/ijsem.0.003187 (2019).

93 Park, S., Park, J.-M., Kang, C.-H. \& Yoon, J.-H. Aliiroseovarius pelagivivens gen. nov., sp. nov., isolated from seawater, and reclassification of three species of the genus Roseovarius as Aliiroseovarius crassostreae comb. nov., Aliiroseovarius halocynthiae comb. nov. and Aliiroseovarius sediminilitoris comb. nov. Int J Sys Evol Microbiol 65, 2646-2652, doi:https://doi.org/10.1099/ijs.0.000315 (2015).

94 Kasai, Y., Takahata, Y., Manefield, M. \& Watanabe, K. RNA-based stable isotope probing and isolation of anaerobic benzene-degrading bacteria from gasoline-contaminated groundwater. Appl Environ Microbiol 72, 3586-3592, doi:10.1128/aem.72.5.3586-3592.2006 (2006).

95 Jung, Y.-T., Park, S., Lee, J.-S. \& Yoon, J.-H. Defluviimonas aquaemixtae sp. nov., isolated from the junction between a freshwater spring and the ocean. Int J Sys Evol Microbiol 64, 4191-4197, doi:https://doi.org/10.1099/ijs.0.068767-0 (2014).

96 Zhang, D.-C. et al. Marinobacter psychrophilus sp. nov., a psychrophilic bacterium isolated from the Arctic. Int J Sys Evol Microbiol 58, 1463-1466, doi:https://doi.org/10.1099/ijs.0.65690-0 (2008).

97 Kim, H. J. et al. Moritella dasanensis sp. nov., a psychrophilic bacterium isolated from the Arctic ocean. Int J Sys Evol Microbiol 58, 817-820, doi:https://doi.org/10.1099/ijs.0.65501-0 (2008).

98 Nogi, Y. \& Kato, C. Taxonomic studies of extremely barophilic bacteria isolated from the Mariana Trench and description of Moritella yayanosii sp. nov., a new barophilic bacterial isolate. Extremophiles 3, 71-77, doi:10.1007/s007920050101 (1999).

99 Hameed, A. et al. Oricola cellulosilytica gen. nov., sp. nov., a cellulose-degrading bacterium of the family Phyllobacteriaceae isolated from surface seashore water, and emended descriptions of 
808

809

810

811

812

$813 \quad 101$

814

815

816

817

818

819

820

821

822

823

824

825

826

827

828

829

830

831

$832 \quad 108$

833

834

835

836

837

838

839

840

841

Mesorhizobium loti and Phyllobacteriummyrsinacearum. Antonie van Leeuwenhoek 107, 759-771, doi:10.1007/s10482-014-0370-6 (2015).

100 Hahnke, S., Tindall, B. J., Schumann, P., Simon, M. \& Brinkhoff, T. Pelagimonas varians gen. nov., sp. nov., isolated from the southern North Sea. Int J Sys Evol Microbiol 63, 835-843, doi:https://doi.org/10.1099/ijs.0.040675-0 (2013).

$101 \mathrm{Li}, \mathrm{Y}$. et al. Photobacterium proteolyticum sp. nov., a protease-producing bacterium isolated from ocean sediments of Laizhou Bay. Int J Sys Evol Microbiol 67, 1835-1840, doi:https://doi.org/10.1099/ijsem.0.001873 (2017).

102 Rajasabapathy, R. et al. Roseovarius azorensis sp. nov., isolated from seawater at Espalamaca, Azores. Antonie van Leeuwenhoek 105, 571-578, doi:10.1007/s10482-013-0109-9 (2014).

103 Pujalte, M. J., Macián, M. C., Arahal, D. R. \& Garay, E. Stappia alba sp. nov., isolated from Mediterranean oysters. Syst Appl Microbiol 28, 672-678, doi:10.1016/j.syapm.2005.05.010 (2005).

104 Colquhoun, D., Hovland, H., Hellberg, H., Haug, T. \& Nilsen, H. Moritella viscosa isolated from farmed Atlantic cod (Gadus morhua). Bull Eur Assoc Fish Path 24, 109-114 (2004).

105 Huang, Z., Guo, F., Lai, Q. \& Shao, Z. Notoacmeibacter marinus gen. nov., sp. nov., isolated from the gut of a limpet and proposal of Notoacmeibacteraceae fam. nov. in the order Rhizobiales of the class Alphaproteobacteria. Int J Sys Evol Microbiol 67, 2527-2531, doi:https://doi.org/10.1099/ijsem.0.001951 (2017).

106 Yan, X.-R. \& Tuo, L. Notoacmeibacter ruber sp. nov., a novel endophytic bacterium isolated from leaf of Rhizophora stylosa. Antonie van Leeuwenhoek 112, 919-925, doi:10.1007/s10482-01901225-3 (2019).

107 O'Halloran, J. A. et al. Pseudovibrio axinellae sp. nov., isolated from an Irish marine sponge. Int J Sys Evol Microbiol 63, 141-145, doi:https://doi.org/10.1099/ijs.0.040196-0 (2013).

108 Shiba, T. Roseobacter litoralis gen. nov., sp. nov., and Roseobacter denitrificans sp. nov., aerobic pink-pigmented bacteria which contain bacteriochlorophyll a. Sys Appl Microbiol 14, 140-145, doi:https://doi.org/10.1016/S0723-2020(11)80292-4 (1991).

109 Kim, Y.-O. et al. Ruegeria halocynthiae sp. nov., isolated from the sea squirt Halocynthia roretzi. Int J Sys Evol Microbiol 62, 925-930, doi:https://doi.org/10.1099/ijs.0.031609-0 (2012).

110 Flood, B. E. et al. Single-cell (meta-)genomics of a dimorphic candidatus Thiomargarita nelsonii reveals genomic plasticity. Front Microbiol 7, doi:10.3389/fmicb.2016.00603 (2016).

111 Beaz-Hidalgo, R., Doce, A., Pascual, J., Toranzo, A. E. \& Romalde, J. L. Vibrio gallaecicus sp. nov. isolated from cultured clams in north-western Spain. Sys Appl Microbiol 32, 111-117, doi:https://doi.org/10.1016/i.syapm.2008.12.002 (2009). 
112 Gomez-Gil, B. et al. Vibrio sinaloensis sp. nov., isolated from the spotted rose snapper, Lutjanus guttatus Steindachner, 1869. Int J Sys Evol Microbiol 58, 1621-1624, doi:https://doi.org/10.1099/ijs.0.65719-0 (2008).

845113 Gómez-León, J., Villamil, L., Lemos, M. L., Novoa, B. \& Figueras, A. Isolation of Vibrio alginolyticus and Vibrio splendidus from aquacultured carpet shell clam (Ruditapes decussatus) larvae associated with mass mortalities. Appl Environ Microbiol 71, 98-104, doi:10.1128/aem.71.1.98104.2005 (2005).

114 BORREGO, J. J. et al. Vibrio tapetis sp. nov., the causative agent of the brown ring disease affecting cultured clams. Int J Sys Evol Microbio/ 46, 480-484, doi:https://doi.org/10.1099/00207713-46-2$\underline{480}$ (1996).

115 Thompson, F. L., Thompson, C. C. \& Swings, J. Vibrio tasmaniensis sp. nov., isolated from Atlantic Salmon (Salmo salar L.). Sys Appl

116 Kojima, H., Watanabe, M. \& Fukui, M. Sulfurivermis fontis gen. nov., sp. nov., a sulfur-oxidizing autotroph, and proposal of Thioprofundaceae fam. nov. Int I Sys Evol Microbiol 67, 3458-3461, doi:https://doi.org/10.1099/ijsem.0.002137 (2017). 
bioRxiv preprint doi: https://doi.org/10.1101/2020.12.28.424624; this version posted December 29, 2020. The copyright holder for this preprint (which was not certified by peer review) is the author/funder. All rights reserved. No reuse allowed without permission.

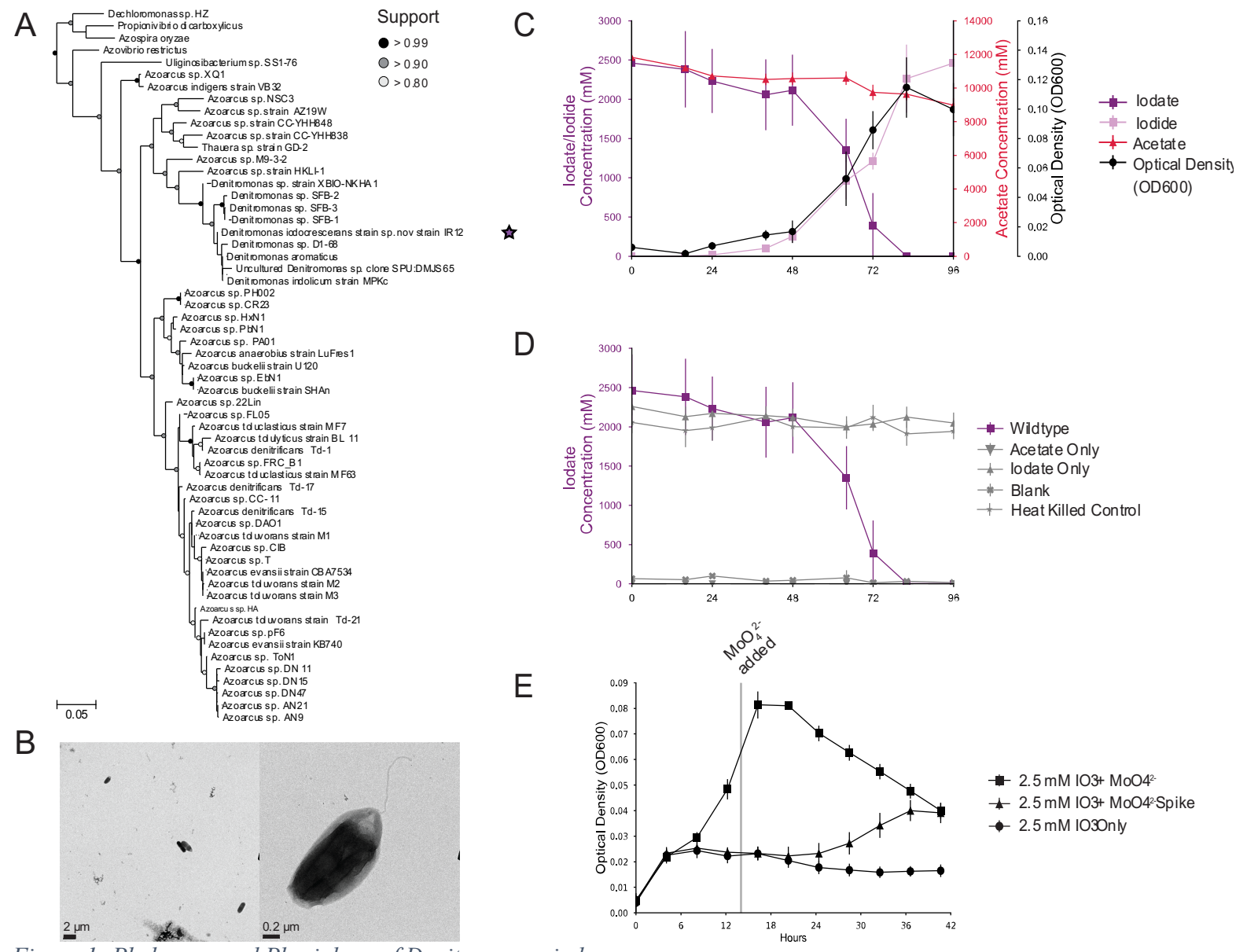

Figure 1: Phylogeny and Physiology of Denitromonas iodocrescerans 
A

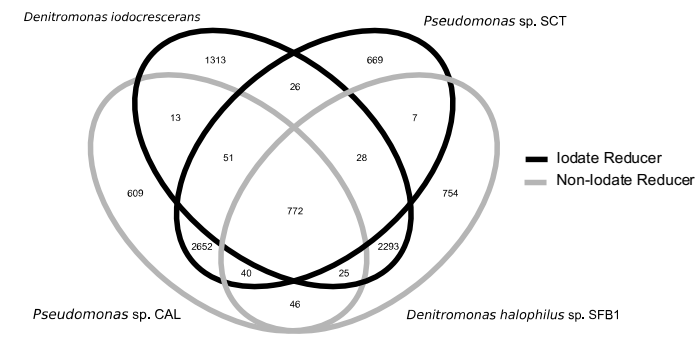

B

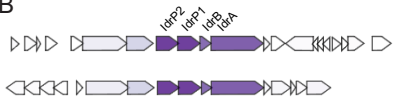

Denitromonas iodocrescerans sp. IR12
C

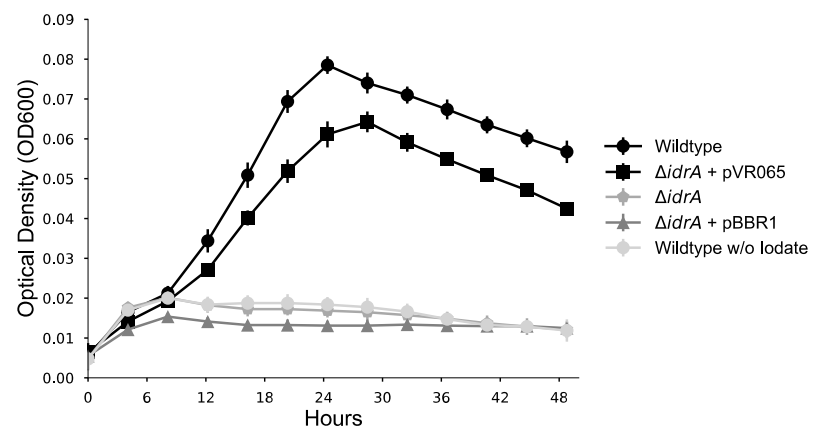
iodate reductase (IdrA) 

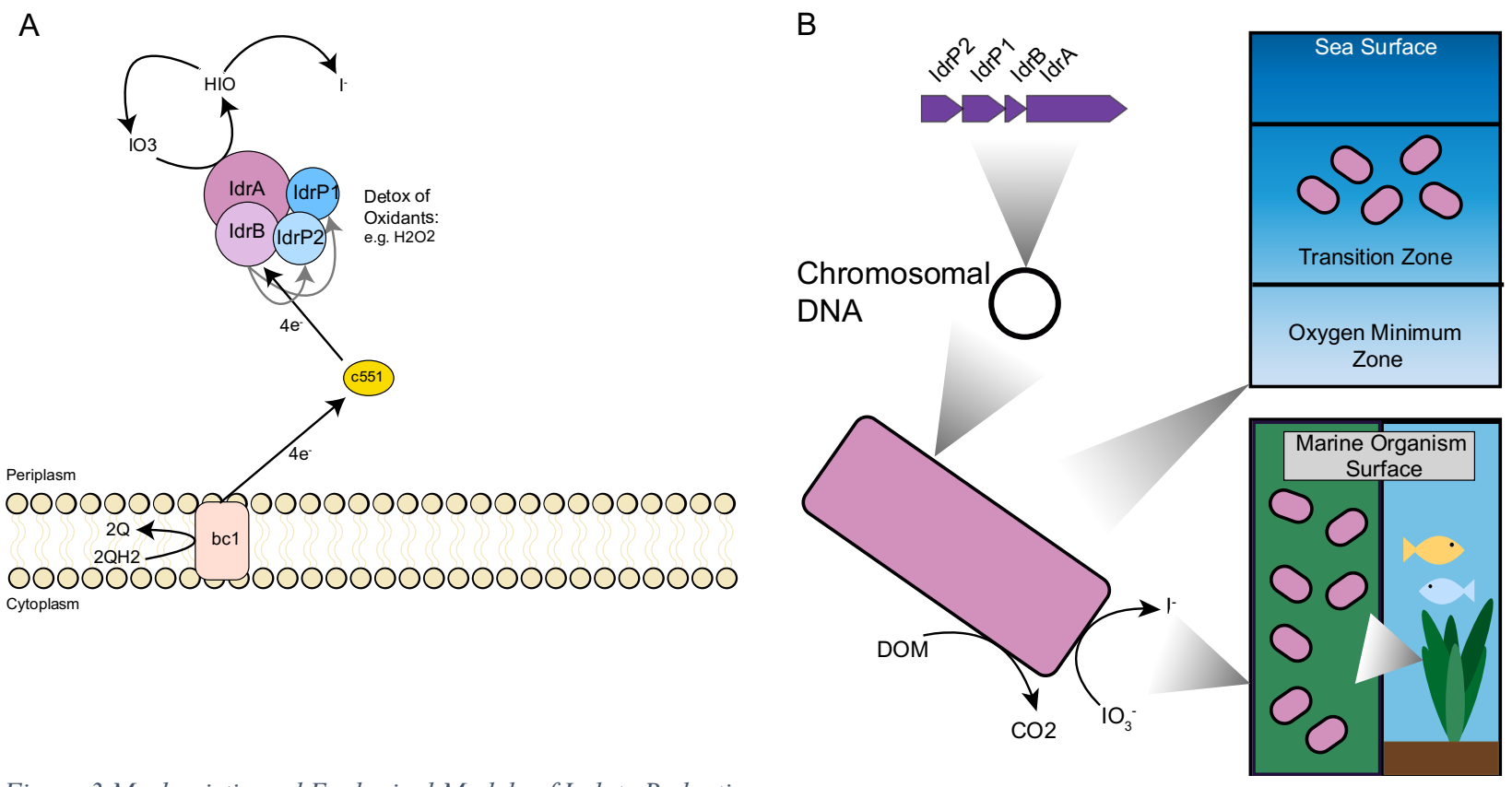

Figure 3 Mechanistic and Ecological Models of Iodate Reduction 
bioRxiv preprint doi: https://doi.org/10.1101/2020.12.28.424624; this version posted December 29, 2020. The copyright holder for this preprint (which was not certified by peer review) is the author/funder. All rights reserved. No reuse allowed without permission.

A

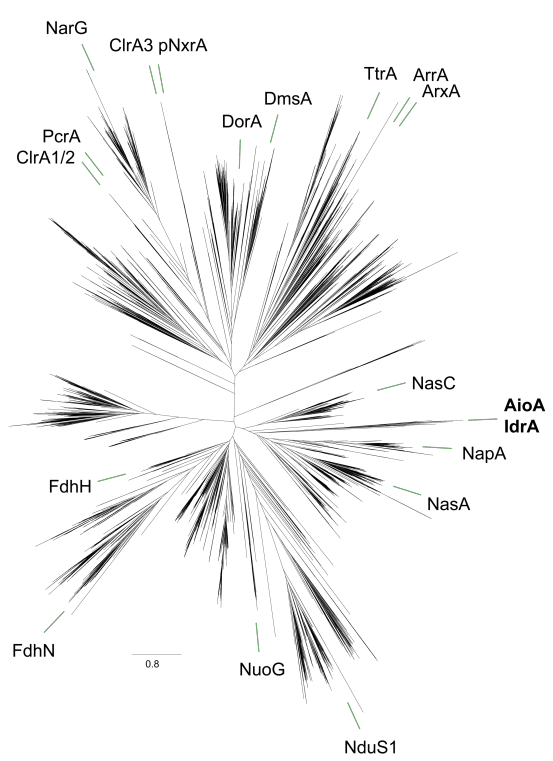

B

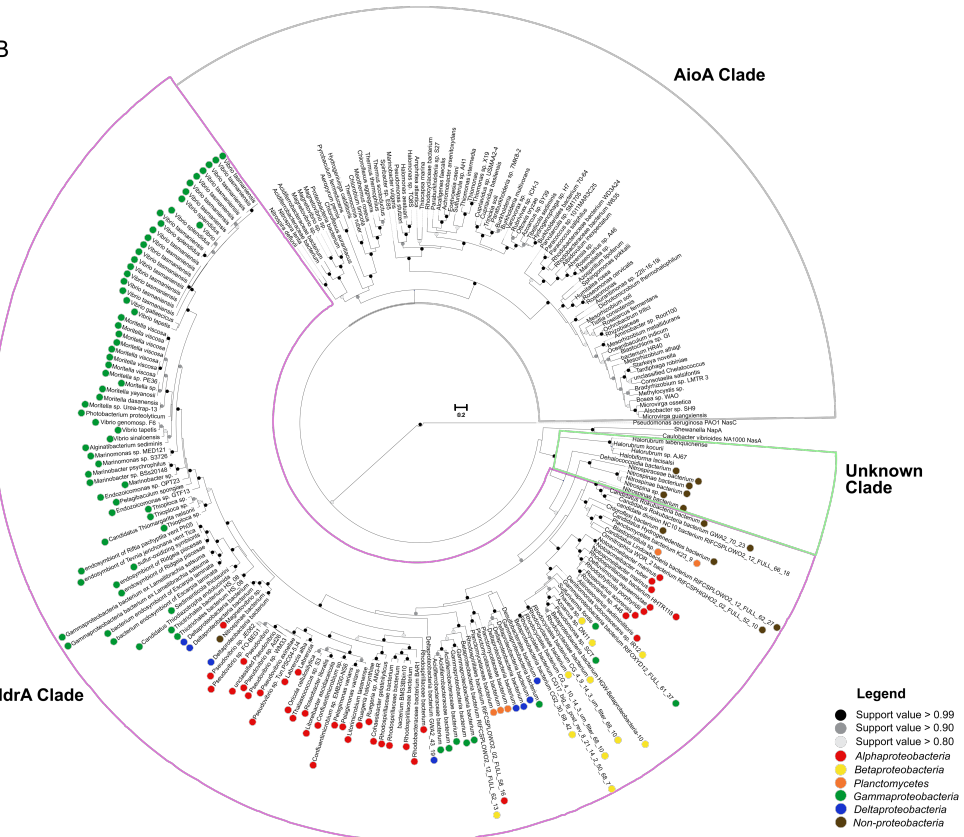

Figure 4 Phylogeny and Taxonomic Distribution of IdrA 
bioRxiv preprint doi: https://doi.org/10.1101/2020.12.28.424624; this version posted December 29, 2020. The copyright holder for this preprint (which was not certified by peer review) is the author/funder. All rights reserved. No reuse allowed without permission.

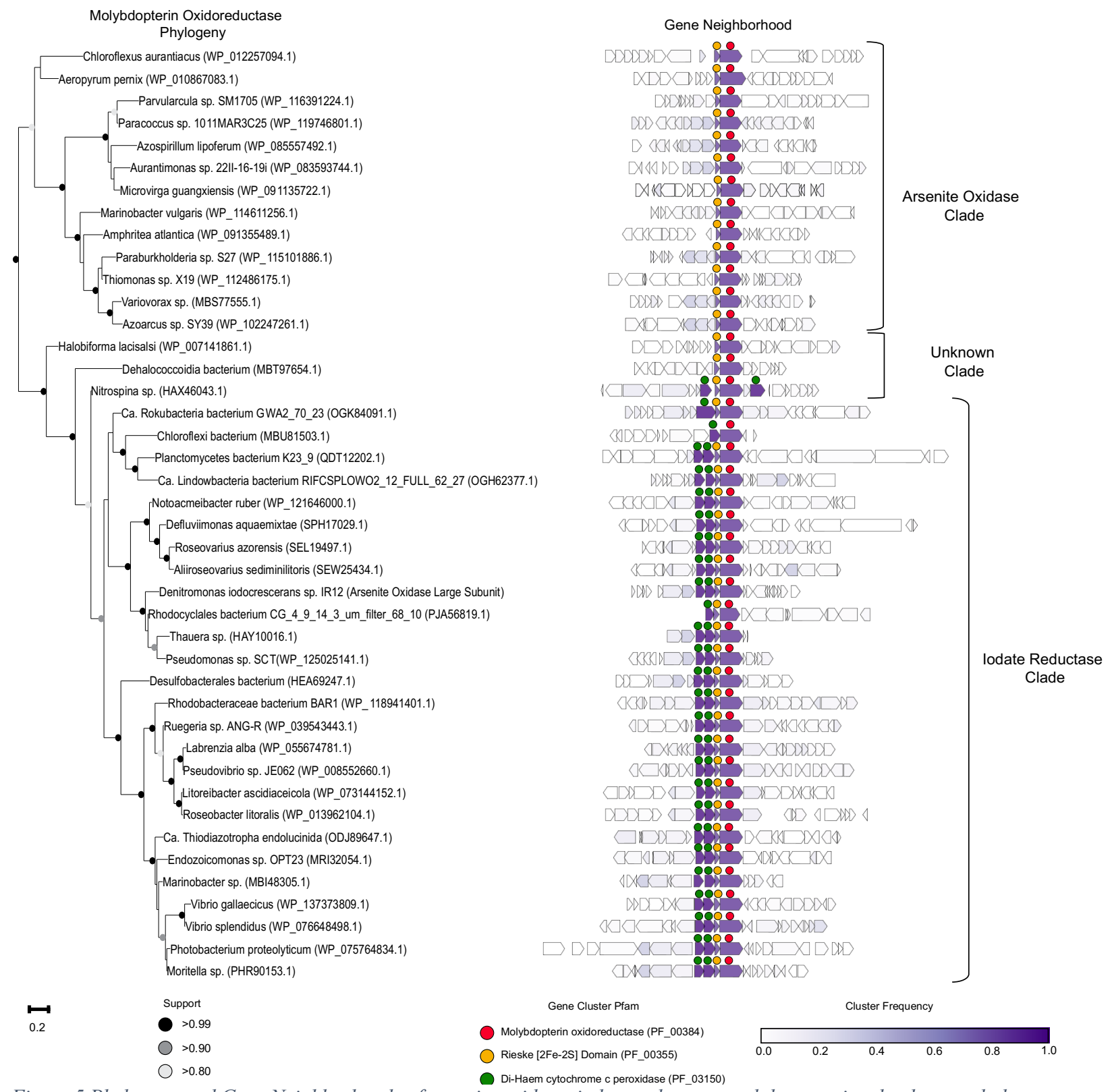

Figure 5 Phylogeny and Gene Neighborhoods of arsenite oxidase, iodate reductase, and the associated unknown clade 
A

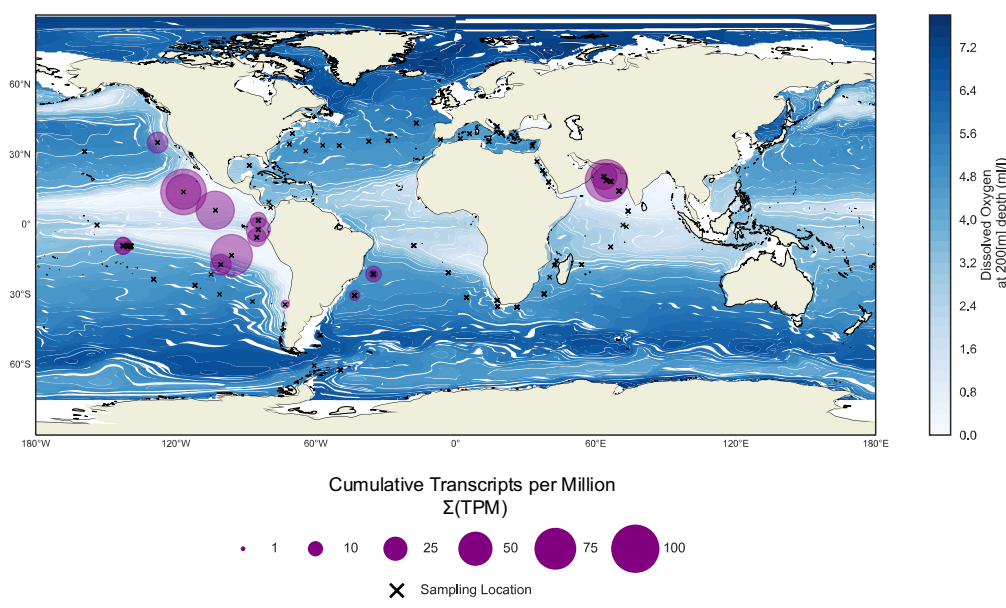

B

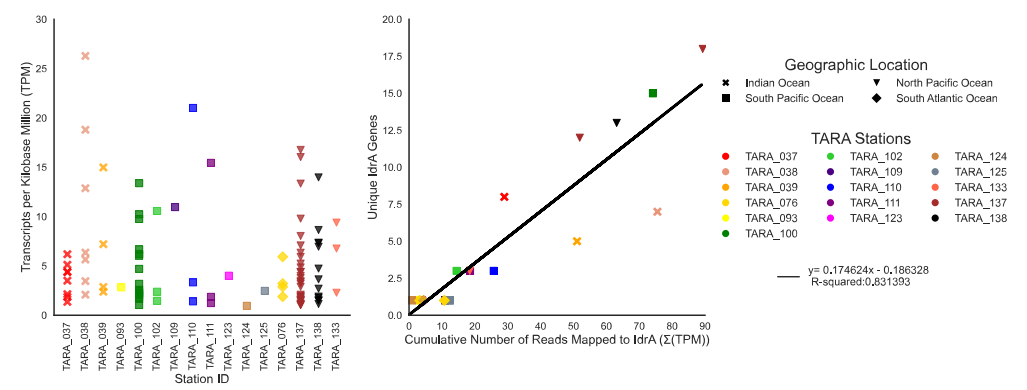

C

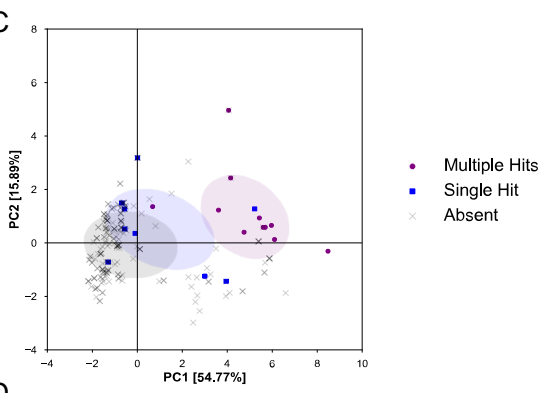

D

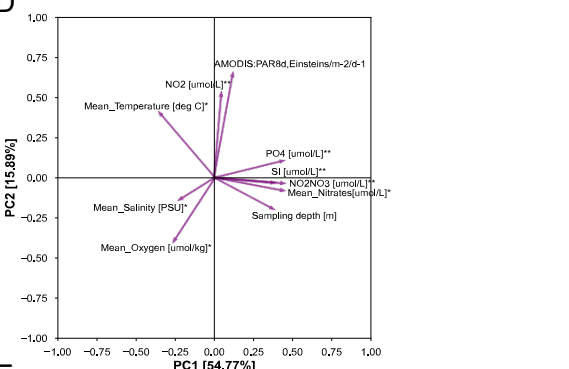

Figure 6 Analysis of Tara Oceans dataset identifies possible ecological niche above oxygen minimum zones 